\title{
Omeprazole and cimetidine in the treatment of ulcers of the body of the stomach: a double blind comparative trial
}

\author{
Danish Omeprazole Study Group
}

\begin{abstract}
Objective-To see whether omeprazole was superior to cimetidine in healing ulcers of the body of the stomach.

Design-Double blind randomised parallel group study of omeprazole versus cimetidine for six weeks with assessment of healing at end of every second week.
\end{abstract}

Setting-Outpatient referrals in 11 centres in Denmark.

Patients-One hundred sixty one patients who satisfied the following criteria: age 18-79; one or more ulcers of body of stomach (that is, at or above the angulus) seen endoscopically within four days before study treatment; no $\mathrm{H}_{2}$ receptor antagonists taken within previous two weeks; no history of gastric surgery and no complications needing surgery; no concurrent treatment or disease that might confound assessment; oral contraception or an intrauterine device being used by women of childbearing age.

Interventions-Omeprazole $30 \mathrm{mg}$ daily (one capsule in the morning) or cimetidine $1 \mathrm{~g}$ daily (one $200 \mathrm{mg}$ tablet thrice daily, two tablets at bedtime) for six weeks. Inactive capsules and tablets provided so that all patients took same number of capsules and tablets daily. Compliance monitored by pill counts.

End point-Endoscopic evidence of accelerated healing of type I gastric ulcers after four weeks of omeprazole.

Measurements and main results-Pain recorded on diary cards and patients assessed after two, four, and six weeks of treatment for clinical state and by endoscopy and biopsy and repeat laboratory tests. Twenty eight patients withdrawn during trial for violations of protocol. At two weeks healing rates were identical in the two treatment groups (omeprazole 41\% (30/73 patients); cimetidine $41 \%$ (30/73)). At four weeks cumulative healing rates were $77 \%$ (53/69 patients) in the omeprazole treatment group and $58 \%(41 / 71)$ in the cimetidine treatment group $(95 \%$ confidence interval of difference between groups $4 \%$ to $34 \%$ ). By six weeks the cumulative healing rates in the two treatment groups differed by only $6 \%(60 / 68$ patients $(88 \%)$ given omeprazole; $53 / 65$ (82\%) given cimetidine). Log rank analysis with ulcer size used as covariable showed a significant difference in healing times in favour of omeprazole. There was no difference in the occurrence of pain relief between the two treatment groups. No serious clinical or biochemical side effects of treatment were noted.

Conclusions-Omeprazole $30 \mathrm{mg}$ daily accelerates healing of ulcers in the body of the stomach as compared with cimetidine $1 \mathrm{~g}$ daily. This effect is more pronounced in ulcers greater than $12 \mathrm{~mm}$ diameter.

\section{Introduction}

Omeprazole, a substituted benzimidazole and potent inhibitor of the proton pump of the parietal cell, reduces gastric acid production more effectively ${ }^{1}$ and heals duodenal ${ }^{2}$ and prepyloric ${ }^{3}$ ulcers more rapidly than cimetidine. So far as we know this is the first comparative trial to be concerned exclusively with ulcers of the body of the stomach. It was undertaken to ascertain whether enhanced acid suppression by omeprazole also accelerates healing of type I gastric ulcers. ${ }^{+}$

\section{Patients and methods}

Outpatients from 11 centres in Denmark fulfilling the following criteria were considered for the study: (a) at least one ulcer in the body of the stomach - that is, an ulcer at or above the angulus - seen at endoscopy within four days before start of treatment (visible loss of substance was required and patients who had only erosions or punctate ulcers were excluded; patients with concurrent prepyloric ulcers - that is, ulcers below the angulus-were also excluded); $(b)$ no treatment with $\mathrm{H}_{2}$ receptor antagonists during the preceding two weeks; (c) no previous gastric surgery (except for simple closure) and no complications necessitating surgical intervention; $(d)$ no concurrent treatment or disease that might confound assessment of results. Laboratory measurements before enrolment included haemoglobin concentration; white cell and platelet counts; serum creatinine, electrolyte, and bilirubin concentrations; serum aspartate aminotransferase and alkaline phosphatase activities; serum albumin concentration; and urinary albumin and glucose concentrations. Patients aged under 18 or over 80 were excluded, as were women of childbearing age who were not using oral contraceptives or an intrauterine device. Multiple biopsy samples were taken to exclude malignancy. Patients gave informed consent and the trial was approved by the regional ethics committee.

The trial had a double blind design. The patients were assigned to receive omeprazole $30 \mathrm{mg}$ daily (one capsule in the morning) or cimetidine $1 \mathrm{~g}$ daily (one $200 \mathrm{mg}$ tablet thrice daily, two tablets at bedtime) by means of a computer generated randomisation list stratified by centre. Inactive, identical looking capsules and tablets were prepared so that all patients received the same number of capsules and tablets daily. The patients were given diary cards and asked to record when they felt pain.

The patients were seen after two, four, and six weeks for clinical assessment, endoscopy with biopsy sampling, and repeat laboratory tests. The number of tablets and capsules returned was recorded. Endoscopy was omitted when healing (complete epithelialisation) had been recorded at the previous visit. Treatment was continued for six weeks regardless of the result of endoscopy. Patients who attended more than three days too early or too late or had taken fewer than three quarters of the prescribed active capsules or tablets were regarded as having violated the protocol. The trial was stopped temporarily (together with all other omeprazole trials), as reported previously. ${ }^{23}$ 
Statistical considerations - We expected that possible promotion of ulcer healing by omeprazole would be easier to detect after four weeks than after six weeks, given findings of previous trials that six weeks of cimetidine heals most ulcers. The result of endoscopy after four weeks of treatment was therefore chosen as the chief end point and the necessary fixed sample size calculated as roughly 75 patients in each group $(2 \alpha=0.05, \beta=0.10$, expected healing rate in the cimetidine group at four weeks $0 \cdot 60$, difference not to be overlooked $0 \cdot 25$ ). We also decided in advance that the statistical analysis must pay special attention to the possible influence of ulcer size on the results. The (two tailed) statistical tests used were Fisher's exact test, the two sample $t$ test, the Mann-Whitney $\mathrm{U}$ test, 5 and the log rank test. 95\% Confidence intervals of the differences between healing rates were also calculated.

\section{Results}

\section{TREATMENT GROUPS}

A total of 161 patients ( 69 men, 92 women) entered the trial. Seventy nine were allocated to receive omeprazole and 82 to receive cimetidine. Table I lists the various characteristics of the two groups.

TABLE I-Characteristics of patients in the two treatment groups (excluding 15 patients who were not available for final analysis)

\begin{tabular}{lcc}
\hline & $\begin{array}{c}\text { Omeprazole } \\
\text { group }\end{array}$ & $\begin{array}{c}\text { Cimetidine } \\
\text { group }\end{array}$ \\
\hline Sex ratio $($ M:F) & $29: 44$ & $31: 42$ \\
Median age (years) (interquartile range) & $60(52-71)$ & $63(50-72)$ \\
No of smokers:non-smokers & $44: 29$ & $43: 30$ \\
Ulcer size: & 13 & 25 \\
$\quad<9 \mathrm{~mm}$ & 20 & 13 \\
$9-12 \mathrm{~mm}$ & 25 & 19 \\
$13-20 \mathrm{~mm}$ & 15 & 16 \\
$\begin{array}{l}\text { Median length of history of ulcer symptoms } \\
\text { (years) (interquartile range) }\end{array}$ & $2(0-8)$ & $2(0-10)$ \\
& &
\end{tabular}

Only minor differences were found, apart from a predominance of small ulcers (size below approximate first quartile) in the cimetidine group.

The results of gastroscopy were analysed after two, four, and six weeks of treatment. Twenty eight patients were excluded from one or more of these analyses for various reasons, including non-compliance before the first visit at which complete ulcer healing was recorded. The notations in parentheses used below - for example, "(cimetidine $0-2-3$, omeprazole $1-2-2$ )"-indicate the cumulative reductions in numbers of patients available for analysis in the treatment groups at two, four, and six weeks. The notations indicate when the patients were withdrawn from the trial.

One patient violated the entry criteria by having a prepyloric ulcer (cimetidine 1-1-1). Biopsy samples from four patients disclosed gastric cancer (omeprazole 3-3-3, cimetidine 1-1-1). Six patients were withdrawn during the trial due to the temporary trial stop (omeprazole 0-2-3, cimetidine 0-2-3). Two patients were withdrawn during the trial because of other disorders (complications after appendicectomy and arthritis) (cimetidine 1-1-2). One patient was withdrawn because of severe urticaria (cimetidine 1-1-1). Six patients did not attend the clinic or refused endoscopy, and in one patient endoscopy was not possible (omeprazole 1-2-2, cimetidine 3-3-4). Six patients did not take the stipulated number of capsules or tablets and one took additional cimetidine (omeprazole 1-2-2, cimetidine 1-1-4). Two patients were seen four days too early or too late at the first visit (omeprazole 1-1-1, cimetidine 1-1-1). The resulting numbers of patients available for analysis of healing after two, four, and six weeks were 73,69 , and 68 in the omeprazole group and 73,71, and 65 in the cimetidine group. In three patients the ulcer of the corpus healed but a new, prepyloric ulcer developed during treatment; their ulcers were regarded as unhealed during the whole treatment period. Additional exclusions had to be made for the analysis of pain relief, as some patients had not filled in their diary cards or taken the stipulated number of capsules or tablets after ulcer healing. The numbers of patients available for that part of the analysis after two, four, and six weeks were 69,65 , and 61 in the omeprazole group and 69 , 66 , and 56 in the cimetidine group.

\section{ULCER HEALING AND PAIN RELIEF}

Table II shows the cumulative healing rates at two, four, and six weeks. At two weeks the healing rates were identical, at four weeks (the main end point of the trial) the healing rate in the omeprazole group was $19 \%$ higher than in the cimetidine group $(95 \%$ confidence interval $4 \%$ to $34 \%$ ), and at six weeks the healing rate in the cimetidine group had almost caught up with that in the omeprazole group. Survival type analysis (log rank test) did not show a statistically significant difference in healing times between the omeprazole and cimetidine treatment groups $(\mathrm{p}=0 \cdot 13)$.

Table II also shows that larger ulcers (size above approximate median) healed more slowly than smaller ulcers, and a confounding effect of the uneven distribution of small ulcers in the two treatment groups could not be excluded. Survival type analysis was therefore repeated on the stratified data (log rank test with ulcer size used as covariable), and this test disclosed a significant difference in healing times in favour of omeprazole $(p=0 \cdot 04)$.

Smoking appeared to have no appreciable effect on ulcer healing.

The average numbers of days with pain during the three two week periods were $5 \cdot 0,4 \cdot 3$, and $2 \cdot 4$ in the omeprazole treatment group and $5 \cdot 5,3 \cdot 8$, and $2 \cdot 4$ in the cimetidine treatment group. The small differences between the treatment groups were not significant (Mann-Whitney U tests, $\mathrm{p}>0 \cdot 2$ ).

TABLE II-Cumulative healing rates at two, four, and six weeks. (Except where stated otherwise, figures in parentheses are percentages)

\begin{tabular}{|c|c|c|c|}
\hline & $\begin{array}{l}\text { Omeprazole } \\
\text { group }\end{array}$ & $\begin{array}{l}\text { Cimetidine } \\
\text { group }\end{array}$ & $\begin{array}{l}\% \text { Difference } \\
95 \% \text { confidence } \\
\text { interval }\end{array}$ \\
\hline \multicolumn{4}{|l|}{ At two weeks: } \\
\hline All patients & $30 / 73(41)$ & $30 / 73(41)$ & $0(-16$ to 16$)$ \\
\hline Ulcer $\leqslant 12 \mathrm{~mm}$ & $22 / 33(67)$ & $23 / 38(61)$ & 6 \\
\hline Ulcer $>12 \mathrm{~mm}$ & $8 / 40(20)$ & $7 / 35(20)$ & 0 \\
\hline \multicolumn{4}{|l|}{ At four weeks: } \\
\hline All patients & $53 / 69(77)$ & $41 / 71(58)$ & $19(40034)$ \\
\hline Ulcer $\leqslant 12 \mathrm{~mm}$ & $30 / 31(97)$ & $31 / 37(84)$ & 13 \\
\hline Ulcer $>12 \mathrm{~mm}$ & $23 / 38(61)$ & $10 / 34(29)$ & 32 \\
\hline Smokers & $23 / 29(79)$ & $18 / 3158)$ & 21 \\
\hline Non-smokers & $30 / 40(75)$ & $23 / 40(58)$ & 17 \\
\hline \multicolumn{4}{|l|}{ At six weeks: } \\
\hline All patients & $60 / 68(88)$ & $53 / 65(82)$ & $6-5+1019$ \\
\hline Ulcer $\leqslant 12 \mathrm{~mm}$ & $30 / 31(97)$ & $31 / 34(91)$ & 6 \\
\hline Ulcer $>12 \mathrm{~mm}$ & $30 / 37(81)$ & $22 / 31(71)$ & 10 \\
\hline
\end{tabular}

Log rank test covering all three time points: $\%=2 \cdot 31 ; \mathrm{df}=1 ; \mathrm{p}=0 \cdot 13$ Log rank test covering all three time points and using ulcer size as covariable: $y=4.39$; $\mathrm{df}=1 ; \mathrm{p}=0.04$.

\section{UNEXPECTED SYMPTOMS AND LABORATORY FINDINGS}

Three patients receiving cimetidine were withdrawn, two because of other diseases and one because of an urticarial reaction. In addition, several complaints and exacerbations of concomitant diseases were recorded in the two treatment groups-namely, omeprazole: allergic oedema (one case), itching (one), diarrhoea (two), tremor (one), polyuria (one), shoulder pain (one), pulmonary oedema (one); cimetidine: itching (one), diarrhoea (one), constipation (two), dizziness 
(two), fatigue (two), insomnia (one), back pain (two).

In one omeprazole treated patient the serum aspartate aminotransferase activity rose from 20 to $82 \mathrm{U} / \mathrm{l}$ (reference range 20-40 U/l) and the alkaline phosphatase activity from 368 to $808 \mathrm{U} / \mathrm{l}$ (reference range $82-224 \mathrm{U} / \mathrm{l}$ ). The patient had no symptoms and the values were almost normal one month after the end of treatment. Two cimetidine treated patients also had raised aspartate aminotransferase activities. Some patients in both groups had abnormal liver function values at entry, which continued unchanged during the trial. In several patients single laboratory values fell outside the normal range, but these abnormalities occurred at random in both groups. The mean change in laboratory values in the two treatment groups from day 1 to day 43 was compared by using the two sample $t$ test. No significant differences were found $(p>0 \cdot 15)$, apart from the difference caused by a slight increase in the serum creatinine concentration in the cimetidine group $(\mathrm{p}=0 \cdot 00004)$.

\section{Discussion}

Previous controlled studies have provided little information on the effect of omeprazole on the healing of ulcers of the body of the stomach. A German multicentre trial in patients with gastric ulcer found no appreciable difference between the effects of omeprazole $20 \mathrm{mg}$ and ranitidine $300 \mathrm{mg}$ daily. ${ }^{6}$ The ulcer was located in the body of the stomach in 53 patients, and the authors mentioned that the healing rate in this subgroup was lower than among the remaining patients, regardless of treatment. In two other trials in patients with gastric ulcer omeprazole was found to be superior to ranitidine but the available abstracts provide no information on sites of the ulcers. ${ }^{i x}$ In one study, which comprised solely patients with prepyloric ulcers, treatment with omeprazole $30 \mathrm{mg}$ was found to be slightly superior to treatment with cimetidine $1 \mathrm{~g} .{ }^{3}$

We conclude that omeprazole $30 \mathrm{mg}$ daily accelerates the healing of ulcers of the body of the stomach as compared with cimetidine $1 \mathrm{~g}$ daily. The results suggest that this effect may be more pronounced in larger ulcers than in smaller ulcers. A trial in patients with mixed gastric ulcers showed that omeprazole $40 \mathrm{mg}$ daily provides higher healing rates than omeprazole $20 \mathrm{mg}$ daily. Possibly, therefore, our results could be improved by using a higher dose.
Our findings also support the conclusion from studies of duodenal ulcers, prepyloric ulcers, and mixed gastric ulcers that short term treatment of peptic ulcers with omeprazole is safe. The safety and efficacy of longer term use of omeprazole have yet to be assessed.

Omeprazole and placebo capsules were kindly provided by A B Hässle, Mölndal, Sweden. Cimetidine and placebo were kindly provided by Smith Kline and French Ltd, Welwyn Garden City, England. We thank Mr Kjeld ClemmensenRotne, Astra-Gruppen A/S, Albertslund, Denmark, for skilfully monitoring the conduct of the study.

Collaborating centres and participating cliniciansDepartment of Medical Gastroenterology, Odense University Hospital: K Lauritsen, L S Laursen, T Havelund, P Bytzer, J Rask-Madsen; Departments of Medical and Surgical Gastroenterology, Frederiksberg Hospital: Dorthe Teilum, J Eriksen, H D Petersen, Karen M Olesen; Department of Surgery, Horsens Hospital: J Ørnsholt; Department of Medicine F, Gentofte Hospital: E Gudmand-Høyer, Hanne S Jensen, J J Rumessen, L Ovesen, Anne G Mikkelsen; Department of Surgery K, Vejle Hospital: C K Axelsson; Department of Surgical Gastroenterology, Rigshospitalet, Copenhagen: Linda Bardram, S Boesby; Department of Surgical Gastroenterology F, Bispebjerg Hospital, Copenhagen: A Hjortrup, J G Stage, O G Backer; Department of Surgery, Ribe Hospital: J H Olsen; Department of Medical Gastroenterology, Herlev Hospital: P Schlichting, M Vilien, H R Wulff; Department of Medical Gastroenterology, Glostrup Hospital: S J Rune, Hanne Skovbjerg; Department of Medicine, Central Hospital, Hillerød: L Elsborg, P J Ranløv.

1 Walt RP, Gomes M de FA, Word EC, Logan KH, Pounder RE. Effét of daily oral omeprazole on 24 hour intragastric acidity. $\mathrm{Br} \mathrm{Med}$ f 1983;287:12-4

Lauritsen K, Rune SJ, Bytzer P, et al. Effect of omeprazole and cimetidine on duodenal ulcer: a double blind comparative trial. $N$ Engl f Med 1985;312: 958-61

3 Lauritsen K, Rune SJ, Wulff HR, et al. Effect of omeprazole and cimetidine on prepyloric gastric ulcer. Double blind comparative trial. Gut 1988;29:249-53. rooks FP. The pathophysiology of peptic ulcer disease. Dig Dis Sci 1985 30 (suppl): $155-295$.

5 Wulff HR, Schlichting P. MEDSTAT. Statistical program for the analysis of controlled therapeutic trials. Version 2. Copenhagen: Astra, 1985.

6 Classen M. Dammann HG, Domschke W, et al. Abheilungsraten nach Omeprazol- und Ranitidin-Behandlung des Ulcus ventriculi. Ergebnisse einer deutschen Multizenterstudie. Disch Med Wochenschr 1985;110:628-33.

Walan A, Bader JP, Classen M, et al. Omeprazole and ranitidine in the Walan A, Bader JP, Classen M, et al. Omeprazole and ranitidine in the
treatment of benign gastric ulcer. An international multicentre study [Abstract]. F Gastroenterol 1987;25:582.

8 Barbara L, Saggioro A, Olsson J, Cisternino M, Franceschi M. Omeprazole $20 \mathrm{mg}$ and ranitidine $150 \mathrm{mg}$ bd in the healing of benign gastric ulcers. An Italian multicentre study [Abstract]. Gut 1987;28:A1341.

(Accepted 10 January 1989)

\section{Hypothyroidism in polymyalgia rheumatica and giant cell arteritis}

\author{
P Wiseman, K Stewart, G S Rai
}

Department of Geriatric Medicine, Whittington Hospital, London N19 5NF $\mathrm{P}$ Wiseman, MRCP, senior registrar

K Stewart, MRCP, senior registrar

G S Rai, FRCP, consultant physician and senior lecturer

Correspondence to:

Dr Rai.

BrMed f 1989;298:647-8
In 1977 a single case report by How et al highlighted the possible coexistence of giant cell arteritis and hypothyroidism and suggested a common cause. 'We set up a study to assess whether this association between hypothyroidism and giant cell arteritis, and also polymyalgia rheumatica, existed and whether it might have an immunological basis.

\section{Patients, methods, and results}

The notes of all patients treated for polymyalgia rheumatica and giant cell arteritis in the department of geriatric medicine at this and the Royal Northern Hospitals during 1981-7 were retrieved and the patients' thyroid state noted. The two conditions had been diagnosed from clinical features, the erythrocyte sedimentation rate, temporal artery biopsy when indicated, and the response to steroids. In patients in whom temporal artery biopsy had not been done the diagnosis was accepted only if steroids had produced the expected clinical response.

Hypothyroid patients who had not been screened for thyroid antibodies were screened prospectively, but only 11 of the 15 patients could be traced. Thyroid function tests were also repeated in these patients. Patients with hypothyroidism were grouped according to whether it had developed before or at the time of presentation or during follow up and were compared with the euthyroid group for age, sex, erythrocyte sedimentation rate, haemoglobin concentration, and platelet count.

We identified 36 patients $(26$ women and 10 men; mean age 80.5 years) with giant cell arteritis (20 patients) or polymyalgia rheumatica (16) (table). Temporal artery biopsy was not done in 11 of the patients with giant cell arteritis as the diagnosis was clear. Thyroid function tests showed that 15 of the 31 